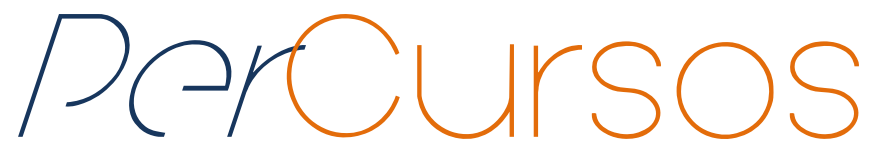

\title{
Territorialidade caiçara expressa nos fazeres-saberes da comunidade do Saco do Mamanguá, Paraty, RJ
}

\section{Resumo}

O artigo apresenta a territorialidade caiçara como expressa nos fazeres com saberes dos comunitários do Saco do Mamanguá, situado ao sul do município de Paraty, RJ. Esta comunidade habita a região desde o século $\mathrm{XVI}$, sendo que está inserida atualmente em um mosaico de Unidades de Conservação (UC). Propomos a discussão de meta social na implantação de uma UC, como também dos conceitos: população tradicional, espaço, território e territorialidade. Concluímos argumentando que os fazeres com saberes da arte de curar revelam uma estratégia, uma relação sociedadenatureza, um modo de estar no mundo que deve ser observado. Propõe-se uma ética do humano, em defesa da biodiversidade que não deve se opor aos direitos das populações locais, mas que há de conciliá-los, faltando a sua implementação.

Palavras-chave: Territorialidade. Caiçaras do Saco do Mamanguá. Fazeres com Saberes. Meta Social.
Maria Aparecida de Sá Xavier

Doutora em Geografia pela

Universidade Federal Fluminense,

Pós-doutor em Geografia pela

Universidade Federal do Espírito

Santo. Pesquisador colaborador: Grupo GETUFF- PPGE-UFF; Grupo

Estudos de Regiões

Metropolitanas, PPGG-UFES;

Grupo Turismo, Espaço e Urbanidades, Turismo-UNIRIO. airamxavier@yahoo.com.br

\section{Para citar este artigo:}

XAVIER, Maria Aparecida de Sá. Territorialidade caiçara expressa nos fazeres-saberes da comunidade do Saco do Mamanguá, Paraty, RJ. Revista PerCursos, Florianópolis, v. 19, n.40, p. 242 - 264, maio/ago. 2018.

\section{DOI: $10.5965 / 1984724619402018242$}

http://dx.doi.org/10.5965/1984724619402018242 


\title{
Territoriality expressed in the making-know of the community of Saco do Mamanguá, Paraty, RJ
}

\begin{abstract}
The article presents the caiçara territoriality as expressed in the actions of the community of Saco do Mamanguá, located south of the city of Paraty, RJ, Brazil. This community inhabits the region since the 16th century, and is currently part of a mosaic of Conservation Units (U.C.). We propose the discussion of a social goal in the implementation of a $\mathrm{CU}$, as well as the concepts: traditional population, space, territory and territoriality. We conclude by arguing that doing them with knowledge of the art of healing reveals a strategy, a society-nature relationship, a way of being in the world that must be observed. It is proposed a human ethic, in defense of biodiversity that should not oppose the rights of local populations, but should reconcile and implement them.
\end{abstract}

Keywords: Territoriality. Caiçaras of Saco do Mamanguá. Making Knowledge. Social Goal. 


\section{Introdução}

A área do estudo está inserida atualmente num mosaico de Unidades de

Conservação: Área de Proteção Ambiental Cairuçu, Reserva Ecológica Estadual da Juatinga (ainda não (re)categorizada), Parque Nacional da Serra da Bocaina e Núcleo Picinguaba Estadual da Serra do Mar (SP), conforme Figura 1. A região tem forte relevância ecológica como área litorânea do tipo "estuarina" ou "ria”, inserida no contexto do bioma Mata Atlântica. Tendo em vista a situação, ocorreu (2002-2004) um esforço empreendido pelo Ibama' (Instituto Brasileiro de Meio Ambiente e dos Recursos Naturais Renováveis) e pelo então CNPT (Centro Nacional do Desenvolvimento Sustentado das Populações Tradicionais) para a implantação de uma Reserva Extrativista Marinha, o que não chegou a se concretizar (Cf. XAVIER, 2004²).

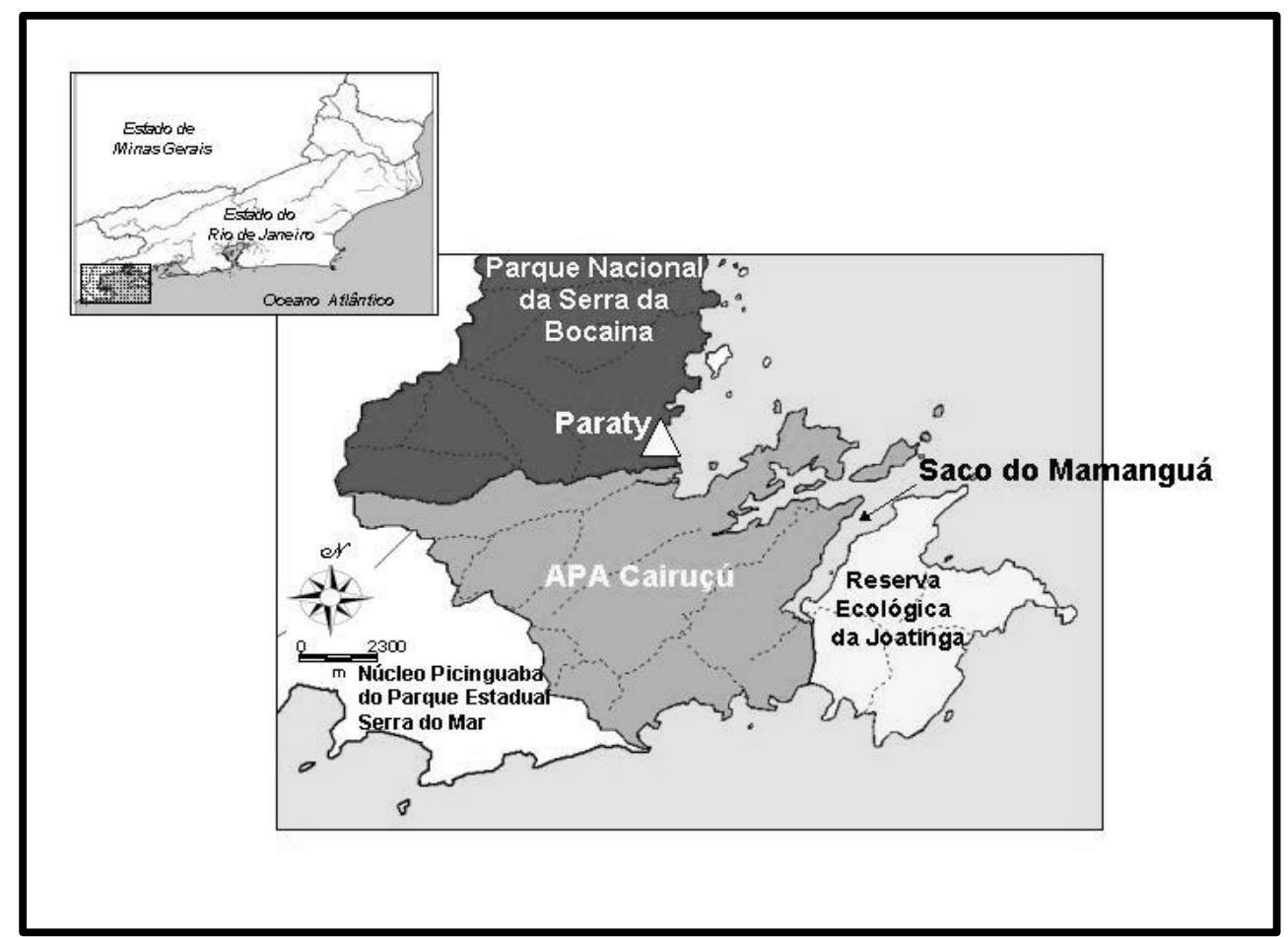

Figura 1 - Contexto geográfico do Mamanguá entre as Unidades de Conservação.

\footnotetext{
${ }^{1}$ A proposta foi veiculada pelo jornal da Fundação Nacional do Meio Ambiente (FNMA) - Informativo de Gerência e Projetos de 11/01/2002 - Projetos Reserva Extrativista Marinha (CV103/00). Com o empenho de pesquisadores como o prof. Antônio C. Diegues, no apoio da criação da Reserva Extrativista Marinha com finalidade de proteção sociocultural, como também empoderamento político e econômico local. Este projeto não se realizou e não temos informações confiáveis atualizadas.

2 Este trabalho de pesquisa ganhou o Prêmio “Rodrigo de Melo Franco" - IPHAN, nível regional, resgate do patrimônio imaterial do estado do Rio de Janeiro, 2007.
} 
Havia o intuito de que essas instituições públicas atuariam como mediadoras e promotoras de ações e recursos que possibilitariam a promoção tanto ecológica quanto social da área, sendo este o cenário daquele momento.

Entretanto, a região não foi e não é um vazio demográfico, pois existem populações residentes desde o século XVI, como trataremos mais adiante. Neste sentido, argumenta-se que os projetos para criação e gestão de Unidades de Conservação, sendo verticais em sua maioria, ao desconsiderarem o ethos ${ }^{3}$ local, causam danos aos grupos, mais do que benefícios. Essas formas locais foram consideradas por Geertz (2002, p. 87) como êmicas, ou seja, como uma experiência próxima, um artefato cultural local, e contrastam com o ético que revela uma experiência distante, um olhar do outro.

Para Santos (2004), o espaço é um constructo social, e como tal, um sistema híbrido, relacional, misto entre objetos e ações, entre o material e o imaterial. Neste sentido, podemos inferir que a territorialidade é uma ação geográfica poderosa, engendrada por agentes sociais, que operam a transformação de um espaço banal em território - dotado de limite e poder. Territorialidade é um dado subjetivo e relacional, que pode ser conhecido e reconhecido através de suas diversas formas e expressões, como um patrimônio cultural, pois revela a identidade do grupo, como veremos adiante. Nesta perspectiva, o texto objetivou apresentar os fazeres com saberes relacionados à arte de curar, como uma expressão de territorialidade, um modo de relação sociedadenatureza. Pretendeu-se também conferir argumentação para a superação do modelo biomédico então vigente, demonstrando a importância da valorização dos saberes patrimoniais de cura para a sobrevivência da identidade cultural local. Conformando uma relação mais horizontal dos profissionais de saúde com a comunidade - relação êmico e ético ${ }^{4}$.

Neste propósito, a pesquisa teve cunho qualitativo, etnográfico. Como parte do método, trouxemos a "observação participante" do comportamento e das

\footnotetext{
${ }^{3}$ Formas de inserção e de relação dos atores com o mundo, caráter, disposição moral e estética, visão de mundo (GEERTZ, 1989, p. 103).

${ }^{4}$ No sentido que Geertz (2002) Ihe dá e aplicada ao contexto desta pesquisa.
} 
representações (narrativas, histórias, artes, rituais mágicos/religiosos, cânticos e danças), entrevistas abertas com roteiro memorizado, fotografia e gravação das conversas, casos, lendas, rezas, músicas e cânticos rituais. O trabalho de campo foi realizado ao longo de três meses na área do estudo, com 20 entrevistas gravadas junto aos atores locais, mulheres e homens adultos de 21 a 87 anos. Os especialistas (benzedeiras, rezadeiras e parteiras), como também os executivos (representantes de associações) da comunidade foram informantes privilegiados ${ }^{5}$.

\section{Panorama geográfico histórico ambiental}

A ocupação do Saco do Mamanguá ocorreu no século XVI, no ciclo da cana-deaçúcar, quando do estabelecimento das fazendas produtoras de açúcar, aguardente e farinha. A decadência econômica da região iniciou com a construção da Estrada de Ferro D. Pedro II, em 1877, tornando o caminho por terra mais atrativo do que a arriscada travessia marítima. Paralelamente, a abolição da escravatura provocou o desmantelamento da estrutura agrícola arquitetada naquele momento. Neste conjunto de situações, uma sociedade foi se compondo como fruto do entrecruzamento étnico e cultural de brancos europeus, índios e negros escravizados. Esta cultura sobreviveu como resistência aos processos históricos sucessivos (DIEGUES \& NOGARA, 1999). Na relação de alteridade com os habitantes de Paraty, a comunidade, que se identifica como "do lugar”, "da roça” e "do Mamanguá”, ficou conhecida como "caiçara”. Essa sociedade se estabeleceu com uma cultura tradicional própria que alternava a agricultura tipo coivara com a pesca artesanal tipo "tresmalho”, “trolha”, “de linha”, “tarrafa” e "rede de espera”. O termo 'caiçara', segundo Sampaio (1987, p. 212), tem origem no vocábulo tupiguarani caá-içara, que significa a estaca, o tapume, o cercado, a trincheira, entre outras. Ao longo do tempo, o termo foi sendo usado para designar as palhoças construídas nas praias para abrigar as canoas e os apetrechos dos pescadores e, posteriormente, nominar os moradores de determinadas praias da parte do Sul e do Sudeste do Brasil, chamados

\footnotetext{
${ }^{5}$ São assim chamados os sujeitos sociais que informam sobre dado assunto pesquisado: informantes privilegiados, em acordo com o método etnográfico (Cf. GEERTZ, 1989, p. 27, "não vale a pena correr o mundo para contar os gatos de Zanzibar").
} 
então de "caiçaras". Diegues \& Arruda (2001, p. 30), com base em Ribeiro (1977), relacionaram as variantes do modelo de povoamento rural no Brasil como cultura sertaneja, cultura gaúcha e cultura caipira.

A cultura caiçara aparece como variante da cultura caipira, mais adaptada ao litoral segundo Queiroz (1973), sendo que possui identidade própria, com modos de vida e expressões que Ihe são característicos. No entanto, Diegues \& Nogara (1999, p. 79) demonstraram que as caiçaras “(...) se distinguem dos 'caipiras', de 'serra-acima' (planalto), por basearem sua subsistência num complexo calendário de atividades socioeconômicas e culturais ligadas à Mata Atlântica e ao litoral”. O assunto não é pacífico. Argumenta-se que caiçaras do Mamanguá conservavam seus saberes, práticas e técnicas, sendo que este patrimônio imaterial vinha sendo ameaçado pela descontinuidade da sua reprodução cultural. Diegues \& Nogara (1999) evidenciaram que, desde a década de 1970, as comunidades na região do Saco do Mamanguá, assim como todo o seu entorno, vêm enfrentando forte pressão imobiliária e turística em razão de sua beleza paisagística e consequente valorização fundiária ${ }^{6}$. A população vivia e ainda vive uma constante insegurança territorial em relação ao seu "lugar”. Como agravante, a área foi considerada endêmica de leishmaniose tegumentar americana ${ }^{7}$.

Na visão de Diegues (1996), Castro (1997) e Lima (2002) a história da criação das unidades de conservação no Brasil teve cunho fortemente impositivo, vertical, com pouca adesão popular. De fato, não ocorreu consulta à sociedade local e as áreas territoriais eram (re)definidas por razões apenas ecológicas, sem maiores preocupações com a sustentabilidade do processo. Em larga medida, a imposição gerou grande concentração de conflitos, principalmente na Amazônia legal, o que estimulou a adoção de novas estratégias para as Unidades de Conservação, como a de manter populações residentes e estabelecer parceria com as mesmas, a fim de promover o uso sustentável dos recursos naturais (LIMA, 2002). Dois modelos foram gerados seguindo essa estratégia socioambiental: a categoria Reserva Extrativista e a Reserva do Desenvolvimento

\footnotetext{
${ }^{6}$ A questão fundiária é também forte problema, já que os comunitários não têm título da terra, mas a posse, e o direito consuetudinário não é reconhecido no Brasil, segundo discussão de Lima (2002, p. 40). ${ }^{7}$ A leishmaniose é uma enfermidade infecciosa da época pré-colombiana, causada por um parasita protozoário do gênero Leishmania, Ross, 1903 (GENARO, 1991, apud. NEVES, 1991, p. 34).
} 
Sustentável. A principal diferença entre elas consiste em que, além do processo histórico de criação, na Reserva Extrativista, o social tem um peso maior do que o ambiental, enquanto que nas Reservas de Desenvolvimento Sustentável, ocorre o contrário, o peso ambiental é maior do que o social. Considerando que na Reserva Extrativista o social tem maior peso, a questão ética do humano constitui um ponto crucial nesse debate. Segundo Lima (2002, p. 37), o artigo 225 da Constituição Federal brasileira declara que: "todos têm direito a um meio ambiente ecologicamente equilibrado, bem de uso comum do povo e essencial à sadia qualidade de vida (...)". O artigo divulga uma concepção democrática da conservação e ainda relaciona o meio ambiente ecologicamente equilibrado à sadia qualidade de vida como um bem essencial e comum de todos. A realização deste direito implica regular as ações humanas que transformam o ambiente (direito ambiental), como também promover ações que garantam uma sadia qualidade de vida aos seres humanos (direitos humanos). Nesse caminho do pensamento, consideramos que se o grande acúmulo de fazeres com saberes ${ }^{8}$ da comunidade rural caiçara do Saco do Mamanguá, inclusive os de cura, não estão sendo considerados, colocam em risco processos de gestão na região e pode avolumar conflitos. Sobre esse assunto, Santos (2003, 2009) nos alerta dos desperdícios da experiência. Faz-se necessário e urgente discutir e definir uma "meta social” comum com a comunidade. Essa meta social poderia dirigir as ações e projetos para a promoção socioambiental na região de modo a promover os indivíduos a sujeitos da conservação, e não apenas objetos dela.

Apresentamos o Saco do Mamanguá como uma localidade dividida em Fundo do Saco, Margem Continental e Margem Peninsular. Existem aproximadamente 119 famílias de moradores, com 527 pessoas, segundo Diegues \& Nogara (1999). O Posto de Saúde está localizado na Praia do Cruzeiro (Margem Peninsular) e a Escola Domingos Gonçalves Abreu, de Ensino Fundamental, na Praia do Curupira (Margem Continental). Havia um templo da Igreja Católica Apostólica Romana (em reconstrução) na Praia do Cruzeiro e

\footnotetext{
${ }^{8}$ Todo fazer está amparado por um corpus de saberes: “Um saber é aquilo de que podemos falar em uma prática discursiva que se encontra assim especificada. (...) Há saberes que são independentes das ciências (que não são nem seu esboço histórico, nem o avesso vivido); mas não há saber sem uma prática discursiva definida, e toda prática discursiva pode definir-se pelo saber que ela forma" (FOUCAULT, 2004, p. 204-205). Portanto, para Foucault, não há relação de poder sem constituição correlata de um campo de saber, nem saber que não suponha e não constitua, ao mesmo tempo, relações de poder.
} 
cinco igrejas pentecostais espalhadas por todo o Saco do Mamanguá. Os comunitários do Mamanguá são considerados "população tradicional” e não “classes populares", diferindo da sociedade abordada por autores como Oliveira (2000), por exemplo. A categoria “classes populares” é tema clássico da Saúde Coletiva e da Saúde Pública, sendo correspondente em geral à população residente nas periferias das grandes cidades, diferenciando-se inclusive da população rural (ou camponesa), como também da dita “população tradicional”. No entanto, esta última categoria, não era (e é pouco ainda) amplamente reconhecida pela área da Saúde e os projetos federais, estaduais e locais, que não levam em consideração as diferenças socioculturais entre população rural e urbana, principalmente nos modos de vida particulares aos diferentes grupos.

Neste sentido, é bom esclarecer que "população tradicional" 9 é categoria recente e que não existe um consenso de definição entre os autores que discutem o tema. No entanto, é possível afirmar que "população tradicional” é uma categoria construída para resolver problemas jurídicos surgidos na criação das Unidades de Conservação que admitia moradores, inicialmente por ocasião da criação das Reservas Extrativistas no Estado do Acre, Brasil (CUNHA\&ALMEIDA, 2001; LIMA, 1997; LITTLE, 2004). Considerada por Lima (2002) de difícil nominação, é dita população “misturada”, pois sem definição étnica. São grupos minoritários de excluídos e invisíveis, habitando geralmente próximo ou nos espaços que foram redefinidos por projetos e políticas como sendo de relevância ecológica. Vale ressaltar que essas sociedades são consideradas de baixo impacto sobre os ecossistemas que habitam (DIEGUES, 1996) em razão de seu modo de vida. Apesar disso, não têm o seu direito consuetudinário reconhecido legalmente, sendo geralmente obrigadas a deixar o seu "lugar" em favor das políticas ambientais, da especulação imobiliária, ou ainda, do turismo desordenado (insustentável) que as empurra cada vez mais para as periferias (favelas) das cidades próximas ${ }^{10}$.

\footnotetext{
${ }^{9}$ E após o decreto 6.040/2007 - Povos e comunidades tradicionais. Disponível em:<http://www.planalto.gov.br/ccivil_03/_at02007-2010/2007/decreto/d6040.htm>.

${ }^{10}$ Em Paraty, temos a Ilha das Cobras como local periférico e sem a infraestrutura da área mais nobre da cidade; em Angra dos Reis, também temos a mesma situação de periferia sem infraestrutura. Esse fato pode ter favorecido a situação de forte criminalidade e insegurança pública atual na região da Costa Verde (RJ), porém necessita de estudos específicos.
} 
Cabe lembrar que o termo "tradicional" foi idealizado pelos formuladores (ambientalistas e acadêmicos) numa contraposição às sociedades ditas "modernas e urbano-industriais", pensando justamente em dar visibilidade e poder político às sociedades camponesas de pequenos agricultores, extrativistas, pescadores, pantaneiros, jangadeiros e caiçaras, entre outros da cultura rústica brasileira (ARAÚJO, 1961; RIBEIRO, 1977; CANDIDO, 1979). Como já dissemos, o tema não é consensual, sendo que a não concordância conceitual sobre a nova categoria se deve à transversalidade que o tema impõe, dificultando uma formulação que dê conta de todos os aspectos suscitados $^{11}$ (BENATTI, 2001; LIMA, 2002,). Apesar disso, essa nova categoria se reveste de carne e osso, assumindo sua "tradicionalidade" (GIDDENS, 1991, p. 44; HOBSBAWM, 1997), indiferente aos conceitos acadêmicos e/ou político-institucionais, conquistando um espaço conceitual, outrora vazio, também “inventado”. Isso ocorre através de pactos e práticas em troca de benefícios e direitos à territorialidade social (LITTLE, 2004), conferindo-lhe substância política significativa, como é o caso das "caiçaras do Saco do Mamanguá”.

\section{Fazeres com saberes de cura no Saco do Mamanguá como expressão de} uma territorialidade

O termo territorialidade, segundo Sack (1986), é uma ação (promovida por seus agentes na relação com o mundo) revelando uma estratégia geográfica poderosa com a finalidade de influenciar e controlar pessoas, fenômenos e relações, delimitando uma área como território. Essas relações estão intimamente ligadas às relações de poder ${ }^{12}$ como um recurso estratégico, uma tática de inserção e controle de determinado grupo social. Na verdade, sãos os meios pelos quais espaço e sociedade estão relacionados num dado tempo histórico percebido (SACK, 1986; XAVIER, 2009). Nessa perspectiva, a

\footnotetext{
${ }^{11}$ Para Lima (2002, p. 41), a população dita tradicional tem um alto custo social devido às restrições que sobrevêm da implantação de uma Unidade de Conservação, mesmo as de uso sustentável. Uma maneira de mitigar esse efeito negativo seria criar mecanismos de compensação social que buscassem ressarcir a sociedade regional pelo benefício à coletividade. Esse benefício pode vir a se concretizar por meio apoio econômico, p. ex., a projetos sociais locais que favoreçam aquilo que a comunidade deseja como "qualidade de vida". Neste sentido, concretiza o empoderamento social.

12 Poder como em Michel Foucault (1979), ações sobre ações.
} 
"relação" ou complexo de "relações" estabelece o lugar, o próprio, o particular de um dado grupo social - seus agentes em relação com um espaço/tempo (HOLZER, 1996). No entendimento de território, Sodré (1988, p. 12) opera com a ideia deste enquanto um espaço-lugar, algo referendado pela história e pela memória dos agentes que o construíram. Para este autor último, o "estar-no-mundo" do sujeito humano é espacial, numa referência a Heidegger. A noção de territorialização para Sodré (1988) é dotada de força ativa e simbólica, força essa demonstrada num sistema relacional entre seres e objetos. No mesmo sentido, Santos (2004, p. 63) também evidencia este aspecto relacional do espaço enquanto um híbrido. Um sistema de objetos e de ações, um misto entre o material e o imaterial. Santos se refere a Godelier (1966, p. 254-255, apud. SANTOS, 2004, p. 102) no encontro de ideias: "todo sistema e toda estrutura devem ser abordados como realidades 'mistas' e contraditórias de objetos e de relações que não podem existir separadamente". Retomando o assunto e usando a conceituação de território e territorialidade dos autores supracitados, podemos entender a territorialidade como um dado subjetivo, relacional, que pode ser conhecido e reconhecido através de suas diversas formas e expressões, como um patrimônio cultural, material e imaterial da comunidade.

Com o objetivo de relacionar os fazeres com saberes de cura da comunidade do Mamanguá com a territorialidade, cabe informar que as sociedades humanas consideradas "tradicionais" sempre buscam alternativas a partir de lógicas de ação endógenas e nem sempre baseadas nas propostas da lógica institucional de saúde hegemônica (OLIVEIRA, 2000). Nesse processo pode assumir uma relação com o entorno na procura de elementos no ambiente que possam integrar tanto as dimensões míticas e mágicas de cura, como sabor, cor, aparência e cheiros, aliados a dada época do seu calendário. Esses elementos são promovidos a materiais curativos através de processos rituais em que a palavra da reza, a entonação e o cântico exercem forte impressão curativa, a eficácia simbólica, segundo Lévi-Strauss (1970, 1975). Esse tipo de relação sociedade/natureza vai construindo um dado corpus de saberes ${ }^{13}$. É nesse saber-fazer que está a legitimidade como verdadeira expressão da territorialidade. Pode-se

\footnotetext{
${ }^{13}$ Como já nos referimos anteriormente.
} 
argumentar que na cosmovisão dessas sociedades com modo de vida diferenciado, a natureza é vista como sacralizada e ativa, a natura naturans, em contraposição à natura naturata, passiva e um mero recurso (SODRÉ, 1988, p. 152). Na acepção dessa natureza viva, Godelier (2001, p. 160-161) informou:

(...) o universo inteiro não é mais composto senão de pessoas (humanas e não-humanas) e de relações entre pessoas. $O$ cosmos torna-se 0 prolongamento antropomórfico dos homens e de suas sociedades. $O$ indivíduo encontra-se ligado ao universo inteiro, que o ultrapassa e que o contém e ultrapassa também a sua sociedade.

Nesse cosmos antropomórfico de Godelier(2001) ou de seres bioantropomórficos, na acepção de Diegues (1996, p. 54) e Morin (1999, p. 195), poderá existir comunicação e comunhão entre seres humanos em estado de comunidade ( $\mathrm{MOSCOVICl,1990)} \mathrm{e} \mathrm{o}$ mundo (material e imaterial). Por fim, para essas comunidades ditas tradicionais, 0 território não tem valor de troca e sim de uso, pois é a base da formação da identidade grupal/individual, importante no reconhecimento de si e por outros.

\section{Representações simbólicas de saúde/doença/cura na comunidade de}

\section{caiçaras do Saco do Mamanguá}

Nas representações simbólicas de saúde/doença/cura foram identificadas quatro categorias distintas, relacionadas no Quadro 1, que seguem a noção da cultura rústica brasileira referida por Araújo (1961) e Candido (1979), entre outros. Os saberes do processo saúde/doença/cura não são saberes isolados, não excluem o saber biomédico, por isso existem doenças que "médico cura" e doenças que "médico não cura". As doenças que "médico não cura" são tratadas pelos especialistas locais com chás, rituais, mágicos ou não, e palavras mágicas. As doenças "híbridas" são aquelas tratadas tanto pelo médico como pelas rezadeiras, benzedeiras e familiares. As doenças que "médico cura" são aquelas que só encontram sentido na cosmovisão biomédica e, nesses casos, recorre-se ao Posto de Saúde. Citaremos aqui um exemplo de doença "que médico não 
cura”, uma doença "híbrida" e um ritual do "benzimento", prescrições e interditos nos “rituais de passagem” e/ou estados liminares da gravidez e pós-parto (resguardo).

Quadro 1 - Síntese de todas as categorias de doenças e estados liminares que requerem cuidados no Saco do Mamanguá.

\begin{tabular}{|c|c|}
\hline $\begin{array}{l}\text { Doenças que } \\
\text { "médico não cura" }\end{array}$ & $\begin{array}{c}\text { aguado, olhado, doença de criança (do preto, do branco e } \\
\text { do vermelho) ou fogo bravo, quebranto, vento virado } \\
\text { espinhela caída, catarro sufocante. }\end{array}$ \\
\hline Doenças híbridas & $\begin{array}{l}\text { cobreiro, izipa, impige ou aipinge, vermes e lombrigas, } \\
\text { gripe ou resfriado, mal de umbigo ou mal dos sete dias } \\
\text { tosse comprida. }\end{array}$ \\
\hline $\begin{array}{l}\text { Doenças tratadas } \\
\text { pelo médico }\end{array}$ & $\begin{array}{l}\text { vertigem (labirintite), pressão alta, elergia (alergia), } \\
\text { doença de tireoide, vista cansada, passamento ou } \\
\text { acabamento (menopausa), diabetes, escorrimento } \\
\text { (“doença de mulher”), hepatite, leishmaniose. }\end{array}$ \\
\hline Estados liminares & $\begin{array}{c}\text { gravidez (e seus interditos), parto, resguardo (e seus } \\
\text { interditos) e velhice }\end{array}$ \\
\hline
\end{tabular}

\section{Vento Virado}

Uma criança pode passar a sofrer de "vento virado" ou "ventre virado" quando eventualmente cair do braço de outra criança, da cama, ou mesmo das mãos de um adulto. Os informantes afirmaram que nessa queda, o "ventre" encosta. Depois disso nada "para" no estômago da criança que vai "secando", tendo diarreia do tipo "verde com sementinha" e vômito. O tratamento é o benzimento com a especialista benzedeira. “Pode levar ao médico, dá o soro, mas só o benzimento é que cura". 


\section{Cobreiro}

Esta doença diagnosticada como "cobreiro" é assim descrita: “(...) fica aquela coisa tudo preta assim (...), que fica aquelas bolinhas e fica correndo água. Aí é certo que aquilo ali é cobreiro" (Mulher, 55 anos, Praia do Cruzeiro). Segundo a informante o “cobreiro" pode ocorrer em qualquer parte do corpo e é transmitido por animais. Neste sentido pode haver cobreiro de sapo, de cobra, entre outros. O ritual do benzimento é realizado por três dias consecutivos e utiliza um "galhinho de pau" molhado em água corrente, recitando palavras mágicas. O ritual é completado com um "Pai-nosso" e uma "Santa Maria entregando para Deus". Segundo a informante "não precisa passar nada, seca apenas com o benzimento". A seguir, as palavras mágicas de um ritual do benzimento:

Pedro andais, Senhor não posso!

O que tem de Pedro? Cobreiro senhor! Curar-se Pedro!

Com o que Senhor?

Com água da fonte e o raminho do monte!

Pedro andais, Senhor não posso! Que tem de Pedro? Cobreiro Senhor! Curar-se Pedro! Com que Senhor?

Com água da fonte e raminho do monte! Aqui mesmo eu corto!

Em nome do pai, do filho e do Espírito Santo

Amém!

Jesus Cristo quando andou pro mundo, muita doença ele curou, Encontrou com Pedro, Paulo que vinha de Belém, Pedro que doença vai por lá? Muita doença Senhor, Cobreiro de sapo, de cobra, de aranha, de tudo os bicho, Então volta e vai curá! Com quê?

Com água da fonte e raminho do monte, assim mesmo eu corto, Em nome do Pai, do Filho e do Espírito Santo, Amém!

\section{A gravidez como um ritual de passagem e o mito do "filho do bicho"}

Nos estados liminares da gravidez, segundo a cosmovisão local, ocorre uma evidente imbricação entre Natureza e Cultura, percebida através do mito "filho de bicho". As mulheres no Mamanguá acreditam que podem engravidar de um caranguejo chamado 
goiá, caso desobedeçam ao interdito de "catar goiá na costeira”, nos primeiros dias ou meses da gestação. A confirmação de que esperava "filho do goiá" vem com o aparecimento de fortes dores e sangramento com coágulos grandes. Sendo assim, a mulher entende que não esperava uma criança, mas sim "filho de bicho goiá"14 . Os coágulos desse aborto espontâneo são percebidos como "bichos" pela cultura local. Nesses casos, "o costume do lugar" é beber "um chá mate bem forte" para aumentar a dor, a fim de ajudar a "nascer os bichos". A crença é que podem nascer um ou vários “bichos", mas enquanto não nascerem todos, a hemorragia não cessa. Este mito configura bem mais do que uma simples explicação para o aborto espontâneo e, apresenta-se como um elo de resistência das tradições locais às contínuas mudanças sociais, as quais está exposta essa sociedade.

$\mathrm{Na}$ interpretação do estudo, esse ser chamado "goiá" tem a propriedade dos "encantados" e os "bichos de fundo" do imaginário amazônico, descritos por MottaMaués (1993, p. 119, p. 131-132) num estudo sobre Itapuá, uma comunidade pesqueira no litoral paraense. Esses seres são entendidos por Diegues (1996: 54-55) como mitos bioantropomórficos que sobrevivem entre às populações de caçadores, extrativistas, pescadores e agricultores itinerantes que vivem em certa medida "afastados" da economia de mercado, em ecossistemas distantes do chamado mundo urbano-industrial. No caso do Mamanguá, não se entende o mito como "sobrenatural", mas sim com o entendimento de uma só Natureza (physis), una e viva (PORTO-GONÇALVES, 1988, p. 2932). O mito dá conta de explicar os acontecimentos, de (re)significar o mundo, dar sentido e ordenar. O ser humano se alimenta dessas construções mentais, e a nossa sociedade ocidental está repleta de mitos, ritos e símbolos (ELIADE, 1991). Como provocação, cabe reflexão sobre as experiências dos híbridos gerados pela biotecnologia, os seres geneticamente modificados ${ }^{15}$.

\footnotetext{
${ }^{14}$ Esta descrição coincide com uma categoria de doença da biomedicina: "Mola Hidatiforme" ou "Doença Trofoblástica Gestacional” (BELFORT \& BUENO, s.d.).

${ }^{15} \mathrm{Cf}$. Haraway (2000), antropologia do cyborgue e seres híbridos.
} 


\section{Parto e Resguardo}

As categorias de parto e resguardo não são consideradas doenças, mas um momento importante para a mulher, sua família e a sociedade. Nessa situação da mulher, os interditos devem ser observados e cumpridos, visto que na representação desses comunitários, um "resguardo quebrado" pode ocasionar uma doença na mulher ou até mesmo levá-la à morte. A categoria "resguardo" é muito rica, visto ser um ritual de passagem, um estado liminar, um período de transição.

Nessa categoria existem dois tempos nas narrativas, o tempo antigo e o tempo de hoje. Segundo uma informante, o tempo antigo é um "tempo dos troncos", "da raiz", um tempo mais "duro", mas um tempo bom. Nesse tempo “dos antigo", havia parteiras no Saco do Mamanguá e as mulheres só faziam seus partos em Paraty "se fosse o caso de alguma complicação mais séria”. As "parteiras" ou "pastorins" recebiam um status na comunidade como "mães de umbigo"; neste sentido, seus "filhos de umbigo" se consideram ainda "irmãos de umbigo". Nos relatos sobre "o parto do tempo antigo" foi possível localizar algumas classificações dos interditos e algumas recomendações do resguardo prescritas pelas parteiras.

Por todo o período do resguardo, a dieta alimentar e os interditos devem ser controlados; os alimentos considerados "carregados" apenas serão permitidos após um ano, quando completa o último período do resguardo. O aleitamento materno é estimulado durante todo o resguardo, inclusive ultrapassando um ano. As prescrições e restrições alimentares dos estados liminares são muito importantes no saber local e apresentam-se em uma classificação exposta no Quadro 2.

No Mamanguá, os alimentos considerados "carregados" correspondem aos com "resma" ou "reima". O alimento com potencial reimoso" é, em geral, relacionado a ocasiões em que os fluxos orgânicos de caráter normal ou patológico aparecem: menstruação, puerpério, distúrbios intestinais, ferimentos ou expectoração, segundo

\footnotetext{
${ }^{16}$ Para Rodrigues (2001, p. 42), o potencial reimoso associa-se sempre a uma situação: o alimento é reimoso para. $\mathrm{O}$ que justifica a expressão: não como porque é reimoso para mim.
} 
Rodrigues (2001, p.140). Por isso, um alimento é reimoso para determinada pessoa em certa ocasião.

Quadro 2 - Representação dos alimentos por classificação

\begin{tabular}{|c|c|c|c|c|c|}
\hline $\begin{array}{c}\text { "Carregado" ou } \\
\text { com "resma" }\end{array}$ & $\begin{array}{c}\text { Não } \\
\text { carregados }\end{array}$ & Peixe bravo & $\begin{array}{c}\text { Peixe } \\
\text { manso } \\
\text { (peixe de } \\
\text { resguardo) }\end{array}$ & $\begin{array}{c}\text { Mariscos } \\
\text { "bravos" }\end{array}$ & $\begin{array}{c}\text { Mariscos } \\
\text { "menos } \\
\text { bravo" }\end{array}$ \\
\hline $\begin{array}{c}\text { Carne de porco } \\
\text { e de pato. Carne } \\
\text { de boi gordo. } \\
\text { Carne de caça: } \\
\text { paca. Abóbora }\end{array}$ & $\begin{array}{c}\text { Galinha } \\
\text { caipira, } \\
\text { frango. } \\
\text { Carne de } \\
\text { boi magra. } \\
\text { Carne de } \\
\text { caça: cotia }\end{array}$ & $\begin{array}{c}\text { Parati, cação, } \\
\text { arraia, tainha, } \\
\text { espada, guete, } \\
\text { caranho e } \\
\text { bonito }\end{array}$ & $\begin{array}{c}\text { Vermelho, } \\
\text { curvina, } \\
\text { embetera, } \\
\text { pescada, } \\
\text { pescadinha, } \\
\text { badejo, bagre } \\
\text { garoupa, } \\
\text { cherne, } \\
\text { carapicú. }\end{array}$ & $\begin{array}{c}\text { Camaranganojo, } \\
\text { sapinanguá } \\
\text { (vongole), }\end{array}$ & Ostra e siri \\
\end{tabular}

No Mamanguá, os peixes, em relação à alimentação do resguardo e dos estados liminares são considerados "bravos" ou “mansos". Essa noção, percebida por oposições, segue a concepção hipocrática que, segundo Rodrigues (2001, p. 135, 136, 138), chegou ao Brasil ainda com os Jesuítas no século XVI, permanecendo nos interstícios da cultura rústica brasileira como uma resistência cultural. Com relação aos alimentos, para a sociedade do Mamanguá, bravo está em oposição a manso, como forte/fraco, quente/frio, cru/cozido. Na cultura local, em momentos ou estados liminares, ou ainda especiais, como o da convalescença, da doença (um ferimento), deve-se evitar comer "peixe bravo", como também comida forte ou carregada, ou ainda alimentos crus, no caso do resguardo.

O "peixe manso", alimentos fracos, frios e cozidos são bons para a mulher no resguardo, como também para os convalescentes, pois alimentam e ajudam a sustentar o corpo nesse período. Nas representações dos comunitários, o alimento "carregado", "bravo" ou com potencial "resma" pode provocar coceiras no corpo ("elergia"), “engrossar o sangue", provocar o reumatismo, impedir que uma ferida cicatrize e que o 
corpo da mulher em puerpério se feche. O efeito da "resma", como o do "bravo", ocorre especialmente sobre a pele de algumas pessoas e em dados períodos.

\section{Considerações finais}

A territorialidade, segundo Porto-Gonçalves (2001, p. 230), revela identidades inscritas nos processos de apropriação de um espaço geográfico; para tanto, essas territorialidades são dinâmicas e mutáveis, materializando em cada momento uma determinada ordem ou configuração territorial, uma topologia social. Para a sociedade tradicional que se territorializa, o território é sua condição de existência, e as múltiplas expressões deste processo dinâmico manifestam-se como um verdadeiro patrimônio cultural. Neste caso, "a Natureza apresenta-se imediatamente ao conhecimento desses como um lugar de permanente observação, pesquisa e reprodução de saberes" (CASTRO, 1997, p.228).

Este artigo, exposto aqui como recorte de pesquisa, demonstra que na arte de cura da sociedade rural caiçara do Saco Mamanguá, se encontra a força da territorialidade expressa na relação sociedade/natureza. Evidenciada nos conhecimentos ou fazeres com saberes dos benzimentos, no uso das plantas com fins medicinais, nos rituais, simpatias, rezas e palavras mágicas. Percebe-se que o tema desta pesquisa se articula num campo interdisciplinar, e revela interfaces em campos disciplinares limítrofes como Geografia, Antropologia e Ciência Ambiental, a fim de dar sustentação teórica e metodológica que a complexidade impõe.

As políticas públicas de saúde no Brasil, em geral, ainda não (re)conhecem dados antropológicos nem tampouco geográficos de territorialidade (não com essa subjetividade), como citado anteriormente. Essa carência tem sido coadjuvante para a não reprodução deste capital social, inviabilizando a socialização das tradições locais para as futuras gerações, provocando ausências de difícil recuperação. Cabe ressaltar que as representações simbólicas demonstradas, põem em relevo a grande distância entre os saberes êmicos e éticos, impactando fortemente a comunidade em seu direito à "saúde e qualidade de vida". 
Por outro lado, as políticas ambientais não dão conta de promoção da saúde das populações residentes, o que as distancia do direito universal à saúde promulgado pela Constituição Federal de $1988^{17}$, no artigo 196. Muito embora após o decreto 6.040/2017, não se possa mais ignorar, pois está previsto. A meta social clama pela implementação de gestão participativa, mesmo cogestão, que poderia dar conta destes impactos nas UC sustentáveis. Argumentamos que a verticalidade nas relações é construída por agentes hegemônicos, como propôs Santos (2005), a quem interessa esta lógica de ação.

Afinal, para Santos (2003, p. 9) “a pobreza da experiência não é expressão de uma carência, mas antes a expressão de uma arrogância, a arrogância de não se querer ver e muito menos valorizar a experiência que nos cerca, apenas porque está fora da razão com que a podemos identificar e valorizar". Com a finalidade de participar da consolidação do direito desses cidadãos em estado de comunidade, este artigo propõe um diálogo dos saberes, como nas ideias de Leff (2001) e Santos ( 2005), porque não existe ignorância em geral nem saber em geral, mas saberes parciais e complementares. A diversidade é celebrada, não como fator de isolamento e fragmentação, mas antes de tudo e, principalmente, como uma condição de partilha, solidariedade e reciprocidade.

Usando a força da repetição, podemos concluir que a territorialidade é, para além de uma expressão de poder, uma estratégia e tática fortemente dependente de relações e posições de seus agentes, evidenciando um modo de estar no mundo, representando um ethos, um modus vivendi. Essas formas ou expressões tão plurais têm direções e criam conformações próprias, que não obedecem necessariamente a uma lógica hegemônica, capitalista e globalizante de apropriação e (re)apropriação do espaço.

Com base nesses termos, propomos uma ética para a sustentabilidade, reivindicada há tanto tempo no documento "MANIFESTO POR LA VIDA"18 (2002) e afirmada por Lima (2002, p. 42), quando defende que a defesa da biodiversidade não

\footnotetext{
17 Há atualmente um campo político em forte disputa, sendo que os direitos e garantias fundamentais conquistados com a constituição cidadã, estão sendo ameaçados no limite, principalmente o direito das populações e povos tradicionais, numa democracia incompleta. O respeito ao modus vivendi, é fundamental para a socio biodiversidade, que muitas vezes não se conhece na inteireza, fazendo com que o 'desperdício da experiência' seja a tônica (Cf. Santos, 2009).

18 Este Manifesto foi elaborado por um grupo de intelectuais atuantes que participaram do Simpósio sobre Ética e Desenvolvimento Sustentável celebrado em Bogotá, Colômbia, nos dias 2-4 de maio de 2002.
} 
Territorialidade caiçara expressa nos fazeres-saberes da comunidade do Saco do Mamanguá, Paraty, RJ Maria Aparecida de Sá Xavier

deve se opor aos direitos das populações locais, pois existem formas e modos de conciliálos, o que falta é implementá-los. 


\section{Referências}

ADAMS, Cristina. Caiçaras na Mata Atlântica. São Paulo: Anablume: FAPESP,2000. 337p.

ARAÚJO, Alceu Maynard. Medicina Rústica. São Paulo: Editora Nacional, 1961. 395p.

BELFORT, Paulo; BUENO, Luiz Gustavo. ABC da Mola (Neoplasia Trofoblástica gestacional). Publicação de educação leiga do Centro de Neoplasia Trofoblástica gestacional, $33^{\text {a }}$ Enfermaria da Santa Casa da Misericórdia do Rio de Janeiro,Instituto Roy Hertz, V edição, s.d. 11p.

BENATTI, José Heder. Presença humana em Unidade de Conservação: um impasse científico, jurídico ou político? In: COPOBIANCO, João P. R. et al. (Orgs). Biodiversidade na Amazônia brasileira: avaliação e ações prioritárias para a conservação, uso sustentável e repartição de benefícios. Belém: Núcleo de Altos Estudos Amazônicos e Instituto de Pesquisa Ambiental da Amazônia. Instituto Socioambiental, 2001. p. 299-305

BRASIL. Constituição: República Federativa do Brasil. Brasília: Senado Federal, C.G.,1988.

CANDIDO, Antonio. Os parceiros do rio Bonito: estudo sobre o caipira paulista e a transformação dos meios de vida. $5^{\circ}$ ed. São Paulo: Livraria Duas Cidades, 1979. 284p.

CASTRO, Edna. Território, biodiversidade e saberes de populações tradicionais. In: CASTRO, Edna; PINTON, Florense. (Orgs.). Faces do trópico úmido: conceitos e questões sobre o desenvolvimento e meio ambiente. São Paulo: Cejup, 1997. p. 221-241.

CERTAU, Michel de. A invenção do cotidiano: artes de fazer. Petrópolis: Vozes, 1990.351p.

CUNHA, Antonio Geraldo da. Dicionário etimológico Nova Fronteira da LínguaPortuguesa. $2^{\text {a }}$ ed. Rio de Janeiro: Nova Fronteira, 1998. 103p.

CUNHA, Manoela Carneiro da; ALMEIDA, Mauro W.B.. Populações tradicionais e conservação ambiental. In: CAPOBIANCO, J. P. R. et al. (Orgs.). Biodiversidade na Amazônia brasileira. Local: Instituto Socioambiental, 2001 .p.184-193.

DIEGUES, Antônio Carlos S.. O mito moderno da natureza intocada. São Paulo: HUCITEC, 1996. 169p.

DIEGUES, Antônio Carlos S.; NOGARA, Paulo José. Nosso lugar virou parque. $2^{\mathrm{a} e d .}$ São Paulo:Nupaub/USP, 1999. 165p.

DIEGUES, Antonio Carlos; ARRUDA, Rinaldo S. V. (Orgs.). Saberes tradicionais e biodiversidade no Brasil. Brasília: Ministério do Meio Ambiente, São Paulo: USP, 2001. $176 \mathrm{p}$. 
ELIADE, Mircea. Imagens e Símbolos: ensaios sobre o simbolismo mágico religioso. São Paulo: Martins Fontes, 1991.

FOUCAULT, Michel. O sujeito e o poder. In: RABINOW, Paul; DREYFUS, Hubert L. Michel Foucault, uma trajetória filosófica (para além do estruturalismo e da hermenêutica). Rio de Janeiro: Forense Universitária, 1995. p.231-249.

FOUCAULT, Michel. Arqueologia do saber. $7^{\mathrm{a}}$ ed. Rio de Janeiro: Forense Universitária, 2004.

GEERTZ, Clifford. A interpretação das culturas. Rio de Janeiro: LTC, 1989.

GEERTZ, Clifford. 0 saber local: novos ensaios em antropologia interpretativa. $5^{\circ}$ ed. Petrópolis: Vozes, 2002.366p.

GENARO, Odair. Leishmaniose tegumentar. In: NEVES, David. Pereira. Parasitologia Humana. $8^{\text {a }}$ ed. São Paulo: Edições Atheneu, 1991, p.34-52.

GIDDENS, Anthony. As consequências da modernidade. São Paulo: Editora UNESP,1991. $177 \mathrm{p}$.

GODELIER, Maurice. O enigma do dom. Rio de Janeiro: Civilização Brasileira, 2001.

GRECO RODRIGUES, Antonio. Buscando raízes. In: TEIXEIRA, Sergio A. (Orgs.).Revista Horizontes Antropológicos, Porto Alegre: UFRGS, , Ano 7, n.16, p.131-143.2001.

HAESBAERT, Rogério. O mito da desterritorialização. Rio de Janeiro: Bertrand Brasil, 2004. 395p.

HARAWAY, Donna. Manifesto cyborgue: ciência, tecnologia e feminismo-socialista no final do século XX. In: SILVA, Tomaz Tadeu da. Antropologia do ciborque - as vertigens do pós-humano. Belo Horizonte: Autêntica, 2000. p. 37-129.

HOBSBAWN, Eric; RANGER, Terence. A invenção das tradições. $3^{\text {a }}$ ed. Rio de Janeiro: Paz e Terra, 1997. p. 9-5; 271-316.

HOLZER, Werther. A geografia humanista: uma revisão. Espaço e Cultura. $n^{\circ}$ 3, Rio de Janeiro: UERJ, 1996, p. 8-19.

LEFF, Enrique. Saber ambiental: sustentabilidade, racionalidade, complexidade, poder. Petrópolis: Vozes, 2001. p.310-326.

LÉVI-STRAUSS, Claude. O feiticeiro e sua magia. In: L.STRAUSS. ANTROPOLOGIA estrutural. Rio de Janeiro: Tempo Brasileiro, 1970. p.183-203.

LÉVI-STRAUSS. A eficácia simbólica. In: L.STRAUSS. ANTROPOLOGIA estrutural. Rio de Janeiro: Tempo Brasileiro, 1975. p.215-236. 
LIMA, Deborah de Magalhães. Equidade, desenvolvimento sustentável e conservação da biodiversidade - os limites da parceria ecológica. In: CASTRO, Edna; PINTON, Florense (orgs). Faces do trópico úmido: conceitos e questões sobre o desenvolvimento e meio ambiente. São Paulo:Cejup, 1997.p.285-312.

. Ética e política ambiental na Amazônia contemporânea. Boletim Rede Amazônica: diversidade sociocultural e políticas ambientais. Rio de Janeiro: LIMA, D. M.;ESTERCI, N.; LENÁ, P. (Eds.), , v.1, n.1, p.37-43, 2002.

LITTLE, Paul. Territórios sociais e povos tradicionais no Brasil: por uma antropologia da territorialidade. Brasília: ICS-UNB, Série Antropologia. Disponível em: $<$ www.unb.br/ics/dan/serie322empdf.pdf $>$. Acesso em 15/01/2004.

MANIFESTO por la vida: por una ética para la sustentabilidad. Ambiente \& Sociedade, São Paulo, , nº10, p. 149-162, jan./junh., 2002. ISSN 1414-753X

MORIN, Edgar. 0 método 3: o conhecimento do conhecimento. Porto Alegre: Sulina, 1999. 287p.

MOSCOVICl, Serge. A máquina de fazer deuses. Rio de Janeiro:Imago,1990. 401p.

MOTTA-MAUÉS. Maria Angélica. Trabalhadeiras e camaradas: relações de gênero, simbolismo e ritualização numa comunidade amazônica. Belém: Editora Universitária UFPA, 1993. 216p

OLIVEIRA, Sonia Acioli de. A construção de saberes e práticas de grupos populares no campo da saúde coletiva. In: TECENDO SABERES. III, IV e JORNADAS DE PESQUISADORES EM CIÊNCIAS HUMANAS V, Rio de Janeiro, 06 de dezembro de 2000. Anais... Rio de Janeiro: CFCH, UFRJ, Fundação Universitária José Bonifácio. Disponível. Um CD-ROM.

PORTO-GONÇALVES, Carlos Walter. Os (des) caminhos do meio ambiente. $6^{\circ}$ ed. São Paulo, 1998. p. 29-31.

. Da Geografia às Geo-grafias: um mundo em busca de novas

territorialidades.Revista Clasco, II Conferência Latinoamericana Y Caribeña de Ciencias Sociais. Universidade de Guadalajara, México, 21-22 de novembro de 2001. p.217-256

QUEIROZ, Maria Isaura P. de. Bairros rurais paulistas: dinâmica das relações bairro rural-cidade. São Paulo: Livraria Duas Cidades, 1973, pp. 3-9; 12-145.

RIBEIRO, Darcy. Os índios e a civilização: a integração das populações indígenas no Brasil

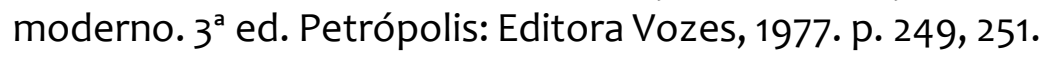

SACK, R. D.. Human Territoriality. Cambridge: Cambridge University Press, 1986.

SAMPAIO, Teodoro. O tupi na geografia nacional. 5ed. São Paulo: Ed. NacionalBrasiliana, 1987.V380. p. 153, 212. 
SANTOS, Boaventura de Sousa. Para uma sociologia das ausências e uma sociologia das e mergências,2002. Disponível em:

https://www.ces.uc.pt/bss/documentos/sociologia_das_ausencias.pdf . Acesso $01 / 12 / 2003$.

. O fórum social mundial: manual de uso. São Paulo: Cortez, 2005. 222p.

SANTOS, Boaventura de Sousa, MENESES, Maria Paula (Orgs). Epistemologias do Sul. Coimbra, PT: Edições Almeldina S/A, 2009.

SANTOS, Milton. A natureza do espaço - técnica e tempo/ razão e emoção. São Paulo: Hucitec, 2004. 384p.

SODRÉ, Muniz. O território e a cidade. Petrópolis: Vozes, 1988. 165p.

XAVIER, Maria A. de Sá. Representações Simbólicas de Saúde/Doença/Cura na comunidade caiçara do Saco do Mamanguá, Paraty (RJ). Dissertação de Mestrado defendida no Programa de Pós-graduação em Ciência Ambiental. Niterói: Universidade Federal Fluminense, 2004.

Ticumbi e a arte de curar na Vila de Itaúnas, C. da Barra, como expressões de espacialidades_2008. Tese de Doutorado. Programa de Pós-graduação em Geografia. Niterói: Universidade Federal Fluminense, 2009. 